\title{
Psychology and the enhancement of pediatric care
}

\author{
Rolando G. Gerena ${ }^{1} \cdot$ Richard B. Gunderman ${ }^{1}$
}

Received: 28 August 2020 / Revised: 28 August 2020 / Accepted: 6 October 2020 / Published online: 20 October 2020

(C) Springer-Verlag GmbH Germany, part of Springer Nature 2020

All radiologists who participate in the care of pediatric patients are familiar with the uncooperative patient - an infant who refuses to drink contrast agent, a toddler who will not lie still for a US examination, or a preschooler who resists urethral catheterization for a voiding cystourethrogram. It is easy to become resigned to such situations, according them little attention or reflection. But doing so would represent a lost opportunity. The ways pediatric patients react to their experiences in the radiology department offer deep insights into the perspectives of children and adolescents, and gaining a better understanding of their psychology opens opportunities to enhance care.

We need but ask the simple question, "Why might a child resist, cry or fail to cooperate with a technologist, nurse or radiologist?" What might appear nothing more than fatigue, fear or obstinacy might in fact reflect deep and complex sensitivity or sense of vulnerability. For example, a child might have good reason to regard the sight of an approaching catheter or needle as a threat. After all, even the health professional wielding it knows that it is likely to cause discomfort or pain. Children, like adults, fear harm, and their past experiences and intuitions about what might prove distressful are often well founded [1].

Radiologists need to look beyond mere behavior and attempt to understand what the operations of the radiology department look like from the point of view of children, as well as their parents and siblings. When children "fail to cooperate," it is often because they do not understand, and in the case of especially young children or those with disabilities, because they are not developmentally equipped to understand. Of course, to say that children do not understand often really

Richard B. Gunderman

rbgunder@iu.edu

1 Department of Radiology,

Indiana University School of Medicine,

702 North Barnhill Drive, Room 1053,

Indianapolis, IN 46202, USA means that they understand differently — they experience the world from a different perspective that, though at variance with an adult health professional's point of view, might be every bit as rich and complex.

Consider, for example, seemingly fundamental concepts such as health, disease, prognosis, treatment and death. Some radiologists might suppose that such terms mean the same thing to everyone, but in fact they are likely to be understood very differently by children of different ages, developmental stages and life experiences. To a physician, health might mean, among other things, the absence of diagnosable disease. To a child, however, health might mean feeling good, and many diagnostic procedures and therapeutic interventions such as confinement, discomfort and pain appear to be direct assaults on well-being.

\section{Stages}

Consider the operations of the radiology department from the points of view of children at various developmental stages. An infant, for example, is in the midst of a period of incredibly rapid growth and development, with new life experiences rushing in at breakneck speed, and essentially completely dependent on parents. Should a member of the radiology staff seek to introduce a change in diet, sleep pattern or parental contact, an infant is quite reasonably distressed. Such a situation can be equally hard on the parent, who is deprived of the opportunity of offering much in the way of verbal explanation or comfort to such a young child. Radiology personnel can help by providing opportunities for touch [2].

Toddlers are becoming more capable, autonomous and reasonable. They have begun to walk and talk, and they enjoy exploration and play [3]. Illness and radiology's role in its diagnosis and treatment often threaten these priorities, constraining what children can do, placing them in the company or care of strangers, and separating them from parents. In many cases, one of their responses might be regression, becoming more infantile in their behavior. One way to help 
toddlers during radiologic procedures is distraction: toys, music, videos and the like can provide them something engrossing on which to focus their attention. This technique can also be helpful for pediatric patients of other ages.

Preschoolers are learning to think for themselves, though in concrete and often literal ways. They have more control than ever over their bodily functions and enjoy taking initiative in exploring and making contact with others. Because children at this stage operate with a sense of personal responsibility, they might associate illness and the radiologist's role in its diagnosis and treatment with punishment, a sign that they must have done something wrong [4]. One way of helping such children cope with their care is storytelling - for example, telling stories about children undergoing similar procedures, which can help to contextualize and thereby de-escalate potentially threatening health care experiences as they unfold.

School-age children are typically very active and verbal. They are mastering a variety of skills, taking on new responsibilities such as chores and homework, and developing an expanded social sense of themselves. Anything that undermines their independence, such as immobilization or isolation, can threaten this sense of self. To compensate for this, health professionals can seek to involve such children in their care, indicating that they play an important role in helping imaging examinations and procedures go well [5]. School-age children are quite conscious of how they appear to others and can respond well to challenges that help them build self-esteem.

Adolescents tend to be even more self-conscious and take the opinions of peers even more seriously. They want to fit in, and aspects of their health care that threaten this - limitations on normal activities, reductions in access to friends and classmates, and changes in appearance, such as loss of hair, are likely to prove difficult. Especially threatening are aspects of illness and care that cause loss of independence or privacy or engender embarrassment. Adolescents are also acutely aware of the effect of their illness on loved ones and might feel guilty about it. Because they can think both hypothetically and symbolically, education is often the best way to put them at ease and secure cooperation.

\section{Respect}

This discussion should not be taken to imply that pediatric patients are somehow inherently inferior to adults. For one thing, many adults harbor fears of health care no less distressing and even more debilitating than those of children. For example, some regard dentists, needles and the bores of MRI scanners with fear. Such reactions are not purely childish emotions - they are present throughout the human lifespan, and the challenge is never to banish them completely but to allay and manage them as effectively as possible. Moreover, children sometimes prove more robust and resilient than their elders - in some cases, it is the child who comforts the parent.

The operative principle is the so-called Golden Rule - the idea that we should treat others as we would wish to be treated. But this rule is more complex than it might appear, challenging us to treat others as we would wish to be treated if we found ourselves in their circumstances. And a key facet of each pediatric patient's circumstances is a stage of development. Fortunately, every radiologist was also once an infant, a toddler, a preschooler, a school-age child and an adolescent, so in attempting to meet patients where they are, we radiologists can rely on our own memories and life experiences as guides. Each of us needs to get more in touch with the child we once were.

Many of us can also rely on our own experiences as parents or caregivers of children. If we can see our own children in our patients, and our patients in our children, we increase our degree of understanding and compassion for what not only patients but also parents and other family members are enduring. Like pediatric patients, parents and family members often find themselves in unfamiliar and stressful situations. The radiologist's mission is to recall, or at least imagine, what such an experience must be like, especially in view of the fact that many parents and family members are in the midst of a crisis associated with potentially serious illness or injury.

We often suppose that the parent teaches the child, the educator teaches the learner, and the physician teaches the patient. But as we take deeper interest in how our work appears from the point of view of the pediatric patient, we begin to appreciate that our patients and their families have much to teach us. Children are communicating as effectively as they can how we are making them feel, and as we learn to tune in to the insights they are offering us, we gain opportunities to become more sensitive, effective and compassionate radiologists. Knowledge and technical proficiency are important, but so too is the ability to connect and care well.

\section{Compliance with ethical standards}

Conflicts of interest None

\section{References}

1. Racine NM, Pillai Riddell RR, Khan M et al (2016) Systematic review: predisposing, precipitating, perpetuating, and present factors predicting anticipatory distress to painful medical procedures in children. J Pediatr Psychol 41:159-181 
2. McGee K (2003) The role of a child life specialist in a pediatric radiology department. Pediatr Radiol 33:467-474

3. Thompson RH (1981) Child life in hospitals: theory and practice. Charles C. Thomas, Springfield

4. Rudolph KD, Dennig MD, Weisz JR (1995) Determinants and consequences of children's coping in the medical setting: conceptualization, review, and critique. Psychol Bull 118:328-357
5. McCabe MA (1996) Involving children and adolescents in medical decision making: developmental and clinical considerations. J Pediatr Psychol 21:505-516

Publisher's note Springer Nature remains neutral with regard to jurisdictional claims in published maps and institutional affiliations. 